\title{
Research on the Producing Mechanism of Abusive Supervision Based on Employees and Its Future Prospect
}

\author{
Ying Pan \\ School of Management, Jinan University, Guangzhou, China \\ Email:249171741@qq.com
}

How to cite this paper: Pan, Y. (2019) Research on the Producing Mechanism of Abusive Supervision Based on Employees and Its Future Prospect. Open Journal of Business and Management, 7, 1880-1890. https://doi.org/10.4236/ojbm.2019.74129

Received: September 2, 2019

Accepted: September 27, 2019

Published: September 30, 2019

Copyright $\odot 2019$ by author(s) and Scientific Research Publishing Inc. This work is licensed under the Creative Commons Attribution International License (CC BY 4.0).

http://creativecommons.org/licenses/by/4.0/

\section{(c) (i) Open Access}

\begin{abstract}
Since the twentieth century, the study of the theory of leadership qualities has been approaching one hundred years. Recently, abuse supervision has caused the focus of researchers in organizational behavior. As a typical representative of disruptive leadership, abusive supervision has become an important topic in the study of leadership behavior. Abusive supervision refers to the sustained verbal or non-verbal hostility committed by the supervisor to the subordinates but does not include the violation of the physical contact class. Although some studies have explored the mechanism of abusive supervision in detail, abusive supervision still exists in the organization. By analyzing the personality traits of abusive leaders and their family environment, the researchers explained why abusive leaders tended to abuse their subordinates from the perspective of social exchange and social studies. This interpretation stays at the general level, and it is difficult to give a reasonable explanation of the reasons why leaders are abusive to specific individual employees. This article summarizes the foreign literature, integrates the research on the mechanism of abusive supervision based on individual level, and then puts forward the future prospect combined with the domestic research.
\end{abstract}

\section{Keywords}

Abusive Supervision, Producing Mechanism, Employees

\section{Introduction}

Abusive management is a destructive leadership behavior that exists in various organizations. It refers to the subordinate's perception of the host's continued linguistic or non-linguistic hostile behavior but does not include physical con- 
tact.

\subsection{Research Reasons}

The reasons for this study of abusive management are as follows. First of all, by combing the literature, we can reasonably explain the mechanism and reasons for the management. Secondly, we can comprehensively comb the theoretical framework of abusive management, and accurately grasp the future research direction and research focus.

\subsection{Research Objectives}

According to the relevant research results of abusive management, it is necessary to explore how to take correct measures to prevent the occurrence of abusive management or the negative effects of link abuse management. This study also helps managers adopt appropriate strategies to deal with abusive management.

\subsection{Definition of Abusive Management}

By looking up the foreign papers, it can be found that different researchers propose different concepts about abusive management according to the research focus, such as toxic leadership, supervisory violations [1], and destructive leadership [2]. When it comes to the definition of abusive management, most scholars have adopted Tepper's point of view to define abusive management as a destructive leader. The verbal or non-verbal continuous hostile behavior of the subordinate's perceived leadership does not include physical contact behavior [3]. In the workplace, Tepper stated that the specific performance is to publicly criticize, ridicule, despise, rude, and rude to subordinates, not to keep promises, commit privacy, suppress power, defame etc. [4].

\subsection{Measurement of Abuse Management}

Tepper described non-physical contact with workplace abusive behavior based on early literature. He excerpted 20 articles related to the description of abuse in marriage and love relationships. He asked the students to sort the fits of these items. Based on the result, he constructed a five-point Likert Abusive Management Scale with 15 entries to measure subordinates' perceptions of leadership linguistic and nonverbal abusive management. This scale is widely used in follow-up studies. Generally, Mitchell [5] conducted exploratory factor analysis and confirmatory factor analysis based on the above scale and divided the scale into two dimensions: aggressive attacks and negative attacks. He formed a reduced version of the abusive management scale from five entries with higher load factors in each of the two dimensions. In addition, researchers reduced the Tepper scale to build a six-entry scale [6]. Thus Shoss [7] established an eight-entry scale. Some researchers [8] have combined the Tepper scale with an attribution type scale to measure individual attribution to abuse management. Some researchers [9] have combined that with comprehensive stress to develop a shame management response strategy scale. 


\section{Different Theoretical Developments in Abusive Management}

Since Tepper [10] proposed abusive management in 2000, many scholars have focused on abusive management. The antecedent variables, consequence variables, and impact mechanisms are discussed. On the one hand, supervisory features, subordinate characteristics, subordinate relationship characteristics and environmental characteristics are important antecedents affecting abusive management. On the other hand, abusive management can also lead to self-directed, organizationally oriented and interpersonal guidance, negative results and spillover effects. Scholars have also proposed different interpretations about the production mechanism of abusive management. Here are the following four aspects.

\subsection{Social Level}

\subsubsection{Social Exchange Theory}

Social exchange theory states that in social relations, people's interaction is mutual dependency and a reaction to the actions of others, not behaviors that are made by one person alone. Researchers [11] found that the abuse management of superiors brings negative emotional experience and interpersonal relationships to lower-level employees. That is, social exchange is a reciprocal behavior. On the one hand, employees at the individual level will have a subjective judgment about the ratio of costs and rewards in exchange. On the other hand, when one party provides assistance or resources to the other party, the latter is obliged to return the person who helped him [12]. Therefore, the negative reciprocal relationship between the supervisor and organization can make the employee feels unfair between pay and return, therefore reducing the amount of effort. When employees think that the abuse of superiors is a threat, they will retaliate against the organization. For example, indifference, bad words, etc. This behavior will also affect colleagues, affecting working smoothly [13].

\subsubsection{Social Learning Theory}

Some researchers [14] focus on observing learning and self-regulation in triggering human behavior, emphasizing on the interaction of human behavior and the environment. Bandura thinks that the interaction is to explore the individual's cognitive, behavioral and environmental factors for human behavior. Based on the theory of social learning, Lian and other scholars [15] first discussed the demonstration effect of abusive leader. From the perspective of social learning, some researchers [16] think that family life is not harmonious and unhappy, thus leading superiors to conduct abusive behavior. Some researchers [17] later confirmed Kiewitz's point of view and carried out a series of adjustments from the leader's angry attitude to expand research.

\subsubsection{Attribution Theory}

Attribution tendency includes three aspects: internal and external causes, stabil- 
ity and controllability [18]. Self-service bias is a comparison of individuals formed in the long-term process. Determined by stable attribution tendency, people with self-service bias tend to maintain self-esteem, denying that they are responsible for failure. They attribute failure to the outside factors. As a self-service deviation, subordinates prefer stable attribution [19]. Subordinates with hostile attribution are more likely to feel the impact of abusive management.

\subsubsection{Social Information Processing Theory}

Social information processing theory states that individuals will seek their own behavior from their surroundings. Therefore, the external environment plays an important role in shaping the behavior of managers. Distrust and hostile attacks on members of the organization are supported and encouraged in the hostile working place. When the superior who leads the abuser feels this atmosphere, he will implement the attack behavior of subordinates to cater to the organizational expectation [20].

\subsection{Moral Level}

Research based on ethical perspectives treats abusive management as an immoral behavior. According to the moral exclusion theory, the reason why leaders exclude their subordinates from fair perspective and implement abusive management is that there are deep differences in perception, conflicts, and low utility of the target object. When characteristics above exist, the leader may be able to treat the subordinates from their own fairness. Moral exclusion theory also emphasizes the consideration of utility when a leader does the implementation of abusive behavior to employees [21]. In addition, some researchers believe that interpersonal relationships influence the morality of leadership. Positive interpersonal feelings will lead to a sense of moral obligation [22], urging leaders to consider whether his or her behavior is in line with organizational fairness when dealing with subordinates.

\subsection{Resource Level}

According to foreign literature research, it can be found that the mechanism of abusive management can also be discussed from the resource level. The research on this aspect is mainly from the theory of resource conservation. The theory of resource conservation believes that individuals will strive to maintain and protect, so that they have access to resources helping them achieve goals [23]. When these resources are subject to actual losses or potential risk losses, an individual feels pressure and invests more resources to control the environment to avoid further resource losses.

According to the theory of resource conservation, individuals with fewer resources are likely to not suffer more loss to enter the loss cycle. In the workplace, some researchers [24] found that abusive subordinates perceive the potential loss of resources associated with social support and cause emotional exhaustion. To 
prevent further loss of resources, they may choose to avoid feedback [25]. However, this kind of behavior will make subordinates lack the necessary feedback from the leadership, thus exacerbating the ambiguity of the role and content of the work, and further improving the emotional exhaustion of the subordinates, forming a vicious circle.

However, under some conditions, the negative impact of abusive management on employee psychology can be effectively relieved. From an individual perspective, individuals with strong social adaptability are more likely to use their own resources to cope with the pressures brought about by abusive management.

\subsection{Individual Level}

As the main body of the implementation of abuse, the individual characteristics of supervisors have an important influence on the abuse management. For example, the gender, age, educational background, marital status, and leadership style of the superior will have an impact. When managers have hostile attribution biases, the destruction of their psychological contracts can lead to aggravation of abusive behavior [26]. Scholars use the metaphor of the kick-dog effect to explain the reasons for that. If a person is subjected to abusive behavior by the manager at the company, when he returns home, he will kick the dog to transfer his anger. Scholars [27] refer to this phenomenon as a turn attack. Similarly, when managers are subjected to abuse, they also turn to attacking subordinates to achieve a psychological balance.

\subsection{Summary}

It can be concluded that once a stupid atmosphere is formed, the leader's abusive behavior is given a certain legitimacy, and the leader is more likely to conduct abusive management [28]. With regard to abusive management, supervisory characteristics and subordinate characteristics, subordinate relationship characteristics and environmental characteristics are important antecedents that affect abusive management. Among them, the individual level-the personality characteristics of employees, the organization of work performance, and the behavior of the words have also been studied by scholars. In abusive management, the study of the behavior of employees who are generally abusers is an important factor in better improving interpersonal relationships between organizations. Therefore, in conjunction with the relevant literature, the following is an inquiry based on the causes of abusive management at the individual level.

\section{Generation Mechanism of Abusive Management Based on the Individual Level}

The theory of Chapter 2 explores the causes of abusive management from the individual level of supervisors. This chapter focuses on the personality characteristics of the employee level to explore the causes of abusive management. As a victim of abusive management, some of the employee's personality traits and 
behaviors provoke abusive management of their subordinates.

\subsection{Personality Traits and Abusive Management}

According to the domestic and foreign literature, based on the personality characteristics of employees, it can be combined with the Big Five personality.

The Big five personality theory specifically includes:

1) Affinity: It refers to whether an individual is easy-going, enthusiastic and good at communicating with others;

2) Neuroticism: It refers to the degree of stability of an individual's emotions. That is, whether an individual often exhibits anxiety, negative emotions such as hostility, depression, self-awareness, impulsivity and vulnerability;

3) Responsibility: It refers to whether the individual has a high achievement orientation and responsible attitude towards the work;

4) Extraversion: It refers to whether the individual is active, outgoing and good at social interaction;

5) Openness: It refers to a wide range of personal interests, creativity and imagination, as well as curiosity about new things and new facts.

Relevant research points out the conscientious characteristics, affinity characteristics and emotions in the Big Five personality. The stability characteristics affect the individual's emotions at work, which in turn affects the individual's perception of abusive management [29].

Personality traits can influence an individual's coping strategies. The study found that individuals with more conscientious characteristics would regard stigma as a challenge. On the other hand, individuals with more open characteristics are more likely to accept and actively respond to changes in the environment.

According to further research by $\mathrm{Wu} \& \mathrm{Hu}[30]$, it can be found that the neuroticism and low responsibility of the subordinates make the subordinates show more anxiety, irritability, impulsivity and unreliability, thus stimulating the supervisory management of the supervisor. On the other hand, these traits make it impossible for subordinates to achieve their own job performance well, thus stimulating the abuse management of superiors.

It can be seen that certain personality traits of individual employees may stimulate their superiors to carry out certain attacks, thus making themselves victims of abusive management. However, certain personal traits of individual employees may also induce themselves to take some kind of aggression against their superiors, thus perceiving more abusive management from this process.

\subsection{Cognitive Theory and Abusive Management}

According to cognitive theory, an individual's perception of abusive management affects his perception and evaluation of abusive management, which in turn affects his behavioral response. Individuals, even if they are not directly affected by negative events, can have negative cognitive and emotional responses 
to the actors of negative events. In the work team, even if the subordinate itself is not abused, if the employee perceives that the leader will conduct abusive management of the specific team members, the subordinates themselves will feel the unfairness of interpersonal interaction.

In addition, cognition based on comparison with others can also affect an individual's cognitive evaluation of abusive management. If subordinates perceive that team leaders are more abusive to themselves and less to other members of the team, the subordinates tend to reduce their suggestions.

From the above research, it can be known that if an employee perceives the abuse management of his or her subordinates, he will also have an unfair feeling; if the individual compares with the abuse suffered by the colleague, the subordinate will reduce his insult.

\subsection{Motivation Theory and Abusive Management}

When discussing the causes of abusive management based on individual levels, it can also be explained by motivation theory. The intrinsic motivation of the subordinate or the attribution to the motivation of the leader's abusive behavior determines his behavioral response to abusive management.

\subsubsection{Attribution Theory and Abusive Management}

According to 2.1.3, the hostile attribution style of the subordinates makes it more susceptible to abusive management, especially when subordinates prefer stable attribution. If the employee thinks that his ability and performance are really unsatisfactory, and the leader abuses him because he hates iron, he tends to internal attribution, and the sense of interaction and fairness will increase. $\mathrm{He}$ will counterattack the leader less. And help leaders engage in some off-the-job work [31]. On the contrary, if employees believe that the cause of abuse is that the personality of the leader is flawed, and the superior is so popular to most people, it tends to conduct external attribution. At this time, the perception of abuse will be more intense [32], and he is more likely to take revenge against leaders. However, if an employee attributes the cause of abusive behavior to his relationship with his superior, he tends to think that he and his superiors should be responsible for the abusive management, which creates a sense of injustice.

\subsubsection{Self-Control Theory and Abusive Management}

According to the theory of self-control, the ability of employees to control themselves and their opportunities affect their response to higher-level abuse. Subordinates with strong self-control ability can better adjust their hostility towards superiors in the case of abuse. Even if employees feel hostile, they will be less revenge for fear of being punished.

\subsection{Findings with Discussion}

Scholars have made quite detailed research on abusive management. The first 
point is to define in detail the conceptual boundaries of abusive management. From the review we can know that most scholars directly quote Tepper's definition of abusive management. However, some scholars are inconsistent with the definition of the abusive management concept boundary. Therefore, it is necessary to discuss the concept boundary in detail in the future, which will enable subsequent researchers to better according to the corresponding studies. Second, abusive management is an important organizational issue. Although this review explores the causes of abusive management based on individual levels, the research perspective should not be limited to this. It should be explored at multiple levels, combined with antecedent variables, cultural variables, resource variables, etc. are analyzed to form a multi-level research orientation.

\section{Future Prospects}

It can be concluded that most of the literature on abusive management comes from Western scholars. China's research on abusive management has made great progress in recent years, and there is no long time for Western scholars to study. In the study of Chinese and foreign scholars, we can find that abusive management is closely related to organizational culture, especially the cultural background of a country. Therefore, follow-up research can consider the study of abusive management in combination with the traditional Chinese cultural background. According to Hofstede's cultural theory framework, Chinese culture has a higher power distance than Western culture. Chinese people are more inclined to diligently save, tolerate and pursue long-term stable life. Whether abusive management plays a restraining or strengthening role still requires further research and discussion by researchers to broaden the research on the causes of abusive management.

\section{Conclusion}

By looking up foreign literature, it can be found that most research scholars have discussed in detail the influencing factors and effects of abusive management. But in fact, abusive management is still common in companies. The employee who is abused cannot handle the relationship with the superior correctly. Therefore, it is still of value to continue to explore the causes of abusive management based on individual levels. It can be known from the above literature review that the research on related abusive management is mainly explained from the social level, the attribution level, the moral level and the resource level. From the individual employee's point of view, the personality characteristics will make different employees feel different levels of abusive management. If we continue to conduct empirical research on any of them in the future, this will play a great role in reducing the negative emotions of employees in the organization. Now, some scholars have made different empirical studies based on different theories. I believe that through continuous efforts. It will definitely promote the progress of employees and the development of enterprises. 


\section{Conflicts of Interest}

The author declares no conflicts of interest regarding the publication of this paper.

\section{References}

[1] Zellars, K.L., Tepper, B.J. and Duffy, M.K. (2002) Abusive Supervision and Subordinates' Organizational Citizenship Behavior. Journal of Applied Psychology, 87, 1068-1076. https://doi.org/10.1037//0021-9010.87.6.1068

[2] Einarsen, S., Aasland, M.S. and Skogstad, A. (2007) Destructive Leadership Behavior: A Definition and Conceptual Model. The Leadership Quarterly, 18, 207-216. https://doi.org/10.1016/j.leaqua.2007.03.002

[3] Tepper, B.J. (2000) Consequences of Abusive Supervision. Academy of Management Journal, 43, 178-190.

[4] Tepper, B.J. (2007) Abusive Supervision in work Organizations: Review, Synthesis and Research Agenda. Journal of Management, 33, 261-289. https://doi.org/10.1177/0149206307300812

[5] Mitchell, M.S. and Ambrose, M.L. (2007) Abusive Supervision and Workplace Deviance and the Moderating Effects of Negative Reciprocity Beliefs. Journal of Applied Psychology, 92, 1159-1168. https://doi.org/10.1037/0021-9010.92.4.1159

[6] Kiewitz, C., Restubog, S.L.D., Zagenczyk, T.J., et al. (2012) Sins of the Parents: Selfcontrol as a Buffer between Supervisors' Previous Experience of Family Undermining and Subordinates' Perceptions of Abusive Supervision. Leadership Quarterly, 23, 869-882. https://doi.org/10.1016/j.leaqua.2012.05.005

[7] Shoss, M.K., Eisenberger, R., Restubog, S.L.D. and Zagenczyk, T.J. (2013) Blaming the Organizational Support and Supervisors' Organizational Embodiment. Journal of Applied Psychology, 98, 158-168.

[8] Burton, J., Hoobler, J. and Scheuer, M. (2012) Supervisor Workplace Stress and Abusive Supervision: The Buffering Effect of Exercise. Journal of Business and Psychology, 27, 71-279. https://doi.org/10.1007/s10869-011-9255-0

[9] Yagil, D., Hasida, B.-Z. and Inbal, T. (2011) Do Employees Cope Effectively with Abusive Supervision at Work? An Exploratory Study. International Journal of Stress Management, 18, 5-23. https://doi.org/10.1037/a0020548

[10] Tepper, B.J., Duffy, M.K., Henle, C.A. and Lambert, L.S. (2006) Procedural Injustice, Victim Precipitation, and Abusive Supervision. Personnel Psychology, 59, 101-123. https://doi.org/10.1111/j.1744-6570.2006.00725.x

[11] Padilla, A., Hogan, R. and Kaiser, R.B. (2007) The Toxic Triangle: Destructive Leaders, Susceptible Followers and Conducive Environments. The Leadership Quarterly, 18, 176-194. https://doi.org/10.1016/j.leaqua.2007.03.001

[12] Gouldner, A.W. (1960) The Norm of Reciprocity: A Preliminary Statement. American Sociological Review, 25, 161-178. https://doi.org/10.2307/2092623

[13] Wei, F. and Si, S. (2013) Tit for Tat? Abusive Supervision and Counterproductive Work Behaviors: The Moderating Effects of Locus of Control and Perceived Mobility. Asia Pacific Journal of Management, 30, 281-296. https://doi.org/10.1007/s10490-011-9251-y

[14] Bandura, A. (1974) Aggression: A Social Learning Analysis by Albert Bandura. Prentice Hall, Upper Saddle River, NJ. https://doi.org/10.2307/1227918

[15] Lian, H., Ferris, D.L., Morrison, R. and Brown, D.J. (2014) Blame It on the Supervi- 
sor or the Subordinate? Reciprocal Relations between Abusive Supervision and Organizational Deviance. Journal of Applied Psychology, 99, 651-664. https://doi.org/10.1037/a0035498

[16] Blau, P.M. (2007) Justice in Social Exchange. Sociological Inquiry, 34, 193-206. https://doi.org/10.1111/j.1475-682X.1964.tb00583.x

[17] Thau, S. and Mitchell, M.S. (2010) Self-Gain or Self-Regulation Impairment: Tests of Competing Explanations of the Supervisor Abusive and Employee Deviance Relationship through Perceptions of Distributive Justice. Journal of Applied Psychology, 95, 1009-1031. https://doi.org/10.1037/a0020540

[18] Yang, J. and Diefendorff, J.M. (2009) The Relations of Daily Counterproductive Workplace Behavior with Emotions, Situational Antecedents, and Personality Moderators: A Diary in Hong Kong. Personnel Psychology, 32, 259-295. https://doi.org/10.1111/j.1744-6570.2009.01138.x

[19] Martinko, M.J., Harvey, P., Brees, J.R. and Mackey, J. (2013) A Review of Abusive Supervision Research. Journal of Organizational Behavior, 34, S120-S137. https://doi.org/10.1002/job.1888

[20] Mawritz, M.B., Folger, R. and Latham, G.P. (2014) Supervisors' Exceedingly Difficult Goals and Abusive Supervision: The Mediating Effects of Hindrance Stress, Anger, and Anxiety. Journal of Organizational Behavior, 35, 358-372. https://doi.org/10.1002/job.1879

[21] Hobfoll, S.E. (2001) The Influence of Culture, Community, and the Nested-Self in the Stress Process: Advancing Conservation of Resources Theory. Applied Psychology, 50, 337-421. https://doi.org/10.1111/1464-0597.00062

[22] Bnadura, A. (1986) Social Foundations of Thought and Action: A Cognitive Social Theory. Prentice Hall, New York.

[23] Hobfoll, S.E. (1989) Conservation of Resources: A New Attempt at Conceptualizing Stress. American Psychologist, 44, 513-524. https://doi.org/10.1037//0003-066X.44.3.513

[24] $\mathrm{Wu}, \mathrm{T}$. and $\mathrm{Hu}, \mathrm{C}$. (2013) Abusive Supervision and Subordinate Emotional Labor: The Moderating Role of Openness Personality. Journal of Applied Social Psychology, 43, 956-970. https://doi.org/10.1111/jasp.12060

[25] Whitman, M.V., Halbesleben, J.R.B. and Holmes, O. (2014) Abusive Supervision and Feedback Avoidance: The Mediating Role of Emotional Exhaustion. Journal of Organization Behavior, 35, 38-53.

[26] Hoobler, J.M. and Brass, D.J. (2006) Abusive Supervision and Family Undermining as Displaced Aggression. Journal of Applied Psychology, 91, 1125-1133. https://doi.org/10.1037/0021-9010.91.5.1125

[27] Tepper, B.J., Duffy, M.K., Hoobler, J. and Ensley, M.D. (2004) Moderators of the Relationships between Coworkers' Organizational Citizenship Behavior and Fellow Employees' Attitudes. Journal of Applied Psychology, 89, 455-465. https://doi.org/10.1037/0021-9010.89.3.455

[28] Mawritz, M.B., Dust, S.B. and Resick, C.J. (2014) Hostile Climate, Abusive Supervision and Employee Ciping: Does Conscientiousness Matter? Journal of Applied Psychology, 99, 737-747. https://doi.org/10.1037/a0035863

[29] Tepper, B.J., Moss, S.E. and Duffy, M.K. (2011) Predictors of Abusive Supervision: Supervisor Perceptions of Deep-Level Dissimilarity, Relationship Conflict, and Subordinate Performance. Academy of Management Journal, 54, 279-294. https://doi.org/10.5465/amj.2011.60263085 
[30] Wu, T.Y. and Hu, C. (2009) Abusive Supervision and Employee Emotional Exhaustion: Dispositional Antecedents and Boundaries. Group and Organization Management, 34, 143-169. https://doi.org/10.1177/1059601108331217

[31] Burton, J.P. and Hoobler, J.M. (2011) Aggressive Reactions to Abusive Supervision: The Role of Interactional Justice and Narcissism. Scandinavian Journal of Psychology, 52, 389-398. https://doi.org/10.1111/j.1467-9450.2011.00886.x

[32] Mawritz, M., Mayer, D., Hoobler, J.M., Wayne, S.J. and Marinova, S.V. (2012) A Trickle-Down Model of Abusive Supervision. Personnel Psychology, 65, 325-357. https://doi.org/10.1111/j.1744-6570.2012.01246.x 